\title{
An Evaluation of Edible Plant Extracts for the Phytoremediation of Lead Contaminated Water
}

\author{
Lovell Agwaramgbo", Charne Thomas", Chardai Grays, Jessica Small, Tajeve Young
}

Chemistry Department, Dillard University, New Orleans, USA.

Email: *lagwaramgbo@dillard.edu

Received April 30 ${ }^{\text {th }}, 2012$; revised June $3^{\text {rd }}, 2012$; accepted July $5^{\text {th }}, 2012$

\begin{abstract}
There is a growing global concern for the environmental and health hazards posed by heavy metal contaminants, especially lead in the soil and ground water. The potential for plant and animal uptake, metabolism, and propagation into food-chain poses great health risks. World communities face a common need to a cheap, efficient, and effective technology to mitigate the growing problem of heavy metal contaminations. The present investigation was undertaken to evaluate the potential of using aqueous extracts of edible vegetables and fruits for the in-situ remediation of lead contaminated water (1300 ppm). The plants used in this study include Mustard Green (Brassica juncea), Spinach (Spinacea oleracea), Collard Green (Brassica oleracea), Bitter Leaf (Vernonia amygdalina), Carrot (Daucus Carota Sativus), Red, Green, and Yellow Bell Pepper (Capsicum Annuum), Tomatoes (Lycopersicon esculentum), Red and White Grape (Vitis vinifera), and Lime (Citrus aurantifolia). After shaking triplicate reaction mixtures lead contaminated water and each substrate for 22 hours at room temperature, lead removal by the substrates were analyzed by EPA Method 6010, using Inductively Coupled Plasma-Atomic Emission Spectrometry (ICP-AES). Results suggest that the order of lead removal is Collard Green (99.8\%) > Spinach (98.7\%) > Mustard Green (98.2\%) > Green Bell Pepper $(97.8 \%)>$ Yellow Bell Pepper (97.75\%) > White Grape (96.7\%) > Carrot (95.5\%) > Red Bell Pepper (94.28\%) > Red Grape > 93.5\% > Tomatoes $(84 \%)>$ Bitter Leaf $(61 \%)$. The study concludes that liquid substrates such as the supernatants from pureed edible tuberous, leafy, and fruity vegetables can effectively remove lead from contaminated water.
\end{abstract}

Keywords: Heavy Metals; Bioremediation; Lead Remediation; Water Contamination; Phytoremediation

\section{Introduction}

Many sites around the globe have been heavily polluted by heavy metals. Lead contamination is one of the most wide-spread group of heavy metal pollutants that contaminate the air, water, and land constituting a major global problem [1-5]. A wide range of human activities are responsible for lead exposure, distribution, and mobilization into or in the environment. Rapid industrializetion and urbanization have led to serious deterioration of the quality and value of the land, water, and air. Majority of homes built before 1978 contain lead-based paints. Degradation of old lead based paint in older homes and unsafe remodeling, sanding, or blasting of these homes can result in the accumulation of lead in the soil $[6,7]$. High lead levels in the soil and its associated risks in urban areas can also be attributed to high densities of traffic that emit leaded gasoline additives and combustion of coal [8], mining activities, wastes and discharges $[9,10]$, automotive exhaust fumes, application of mu-

\footnotetext{
*Corresponding author.

"Louisiana Alliance for Minority Participation Scholar.
}

nicipal waste water [11], manufacture and use of agricultural fertilizers, insecticides and pesticides [12], and waste disposal in landfills [13]. Other products and materials that contain lead include but are not limited to glazed ceramics and toys [14], lead containing plumbing pipes and sinks, television glass, ammunitions, and batteries, $\mathrm{x}$-ray shields, fetal monitors, electrical equipment, and some lead-roofing materials.

Despite global efforts to reduce environmental lead exposure over the past several decades, lead pollution and exposure pose grave and urgent environmental and public health concerns [15-18]. Lead is a non-degradable toxic substance whose exposure to children has been reported to cause impaired mental development, reduced cognitive ability, learning difficulties, and low IQ [7,1922], low quantitative skills [23], and neurotoxicity [24]. Lead is potentially harmful to adults and can cause brain, neurological, kidney, reproductive system, and liver damage [25], and renal disease [26].

Over the last decade, considerable research has focused on developing cheap and effective solutions for the treating contaminants in soil and water. Phytoremedia- 
tion technique has shown promise in the mitigation of organic contaminants [27-29], and petroleum hydrocarbons [30]. However, the technologies for heavy metal contaminated soil has met mixed success because of cost prohibitive ex-situ processes that require excavation and removal $[31,32]$. In practice, in-situ remediation technologies are favored over ex-situ methods for contaminant mitigation (detoxification, neutralization, degradation, or immobilization).

Utilization of plants for the clean up of heavy metals from aquatic environment is beginning to gain attention. Technologies for heavy metal contaminated water include electrochemical deposition and precipitation [33,34].

The later introduces other chemicals into the water and environment. Emerging research reports have shown that some substrates have the potential to remove heavy metals from contaminated water [35-38].

Recently, Agwaramgbo reported that charcoal, clay soil, and mustard green and spinach [39] and Salmon Fishbone [40] significantly removed lead from contaminated water. The present paper aimed at evaluating the extracts from edible leafy, tuberous, and fruity plants for the remediation of lead contaminated water.

\section{Materials \& Methods}

\subsection{Preparation of Lead Nitrate Solution 1300 ppm}

Using an analytical balance, $1.3 \mathrm{~g}$ of lead Nitrate from Fisher Scientific (L6200) was dissolved in enough deionized water (added incrementally) to give $1000 \mathrm{ml}$ of solution. Then a stirring bar was dropped into the volumetric flask and the mixture was stirred until all the lead was completely dissolved. The flask was wrapped with aluminum foil to avoid much exposure to light while the solution continued to stir at room temperature until it was used.

\subsection{Preparation of $650 \mathrm{ppm}$ of Lead Nitrate Solution}

To $25 \mathrm{ml}$ of the $1300 \mathrm{ppm}$ lead nitrate solution prepared above was added $25 \mathrm{ml}$ of deionized water. This represented a control for the dilution that will occur when 25 $\mathrm{ml}$ of plant extract supernatants are added to $25 \mathrm{ml}$ of the $1300 \mathrm{ppm}$ lead solution, respectively. The resulting solution was vortexed using a Genie 2 vortex and stirred to mix.

\subsection{Preparation of the Supernatants from Leafy Vegetables: Spinach, Mustard Green, Collard Green, Bitter Leaf}

Mustard Green, Spinach, and Collard Green were bought from a local market while the Bitter Leaf was obtained from a local garden. Each leafy vegetable (100 g) was washed with deionized water and patted dry with kimwipes. The $100 \mathrm{~g}$ of each vegetable was respectively pureed in a regular kitchen blender using $200 \mathrm{ml}$ of deionized water. Each puree was filtered using a white handkerchief bought from a local Wal-Mart store. The filtrate was put into four $50 \mathrm{ml}$ centrifuge tubes and centrifuged at $3000 \mathrm{rpm}$ for 10 minutes using a Thermo Centra CL2 bench-top centrifuge. Using disposable pipettes, three $25 \mathrm{ml}$ portions of each resulting supernatant was carefully transferred into three $50 \mathrm{ml}$ centrifuge tubes, respectively. The tubes were capped, labeled, and put in the refrigerator for later use within one hour.

\subsection{Preparation of the Supernatants from Fruity Vegetables: Red, Green, and Yellow Bell Pepper, and Tomatoes}

Following the procedure used for the leafy vegetables above, $100 \mathrm{~g}$ of each fruity vegetable was pureed, filtered and centrifuged. Each resulting supernatant was transferred into three $50 \mathrm{ml}$ centrifuge tubes in $25 \mathrm{ml}$ portions, respectively. The tubes were capped, labeled, and put in the refrigerator for later use within one hour.

\subsection{Preparation of the Supernatants from Fruits: Red and White Grape}

Following the procedure used for the fruity vegetables above, $100 \mathrm{~g}$ of each fruit (white and red grape) was pureed, filtered and centrifuged. Each resulting supernatant was transferred into three $50 \mathrm{ml}$ centrifuge tubes in $25 \mathrm{ml}$ portions, respectively. The tubes were capped, labeled, and put in the refrigerator for later use within one hour.

\subsection{Preparation of Lime Supernatant}

Following the procedure used for the fruity vegetables above, lime fruits bought from a local store were washed, dried, and peeled. $100 \mathrm{~g}$ of the peeled fruit was pureed with $200 \mathrm{ml}$ of deionized water, filtered and centrifuged. Each resulting supernatant was transferred into three 50 $\mathrm{ml}$ centrifuge tubes in $25 \mathrm{ml}$ portions, respectively. The tubes were capped, labeled, and put in the refrigerator for later use within one hour.

\subsection{Preparation of Carrot Supernatant}

Following the procedure used for the fruits above, $100 \mathrm{~g}$ of carrot bought from a local store were washed, dried, and pureed with $200 \mathrm{ml}$ of deionized water. The resulting mixture was filtered and centrifuged. Each resulting supernatant was transferred into three $50 \mathrm{ml}$ centrifuge tubes in $25 \mathrm{ml}$ portions, respectively. The tubes were capped, labeled, and put in the refrigerator for later use within one hour. 


\section{Reaction of the Plant Supernatants}

\subsection{Reaction of $1300 \mathrm{ppm}$ of Lead Solution with the Leafy Plant (Spinach, Mustard Green, Collard Green, and Bitter Leaf) Supernatants}

Into each triplicate centrifuge tubes containing $25 \mathrm{ml}$ of the spinach and mustard green, collard green, and bitter leaf supernatants, respectively was added $25 \mathrm{ml}$ of the lead nitrate solution $(1300 \mathrm{ppm})$ prepared above. The twelve tubes and their contents along with triplicate tubes containing the $1300 \mathrm{ppm}$ lead solution and its two-fold diluted solutions were vortexed, tightly secured on the rack of a heavy duty Eberbach 6000 shaker, and agitated for 24 hours at room temperature.

\subsection{Reaction of $1300 \mathrm{ppm}$ of Lead Solution with the Fruity Vegetables (Bell Pepper \& Tomatoes) Supernatants}

Into each triplicate centrifuge tubes containing $25 \mathrm{ml}$ of the red, green, and yellow pepper and tomatoes supernatants, respectively was added $25 \mathrm{ml}$ of the lead nitrate solution $(1300 \mathrm{ppm})$ prepared above. The twelve tubes and their contents were vortexed, tightly secured on the rack of a heavy duty Eberbach 6000 shaker, and agitated for 24 hours at room temperature.

\subsection{Reaction of $1300 \mathrm{ppm}$ of Lead Solution with the Fruits (Red and White Grape, and Lime) Supernatants}

Into each triplicate centrifuge tubes containing $25 \mathrm{ml}$ of the grape and lime supernatants, respectively was added $25 \mathrm{ml}$ of the lead nitrate solution (1300 ppm) prepared above. The nine tubes and their contents were vortexed, tightly secured on the rack of a heavy duty Eberbach 6000 shaker, and agitated for 24 hours at room temperature.

\subsection{Reaction of $1300 \mathrm{ppm}$ of Lead Solution with the Tuberous Vegetable (Carrot) Supernatant}

Into the triplicate centrifuge tubes containing $25 \mathrm{ml}$ of the carrot supernatants were respectively added $25 \mathrm{ml}$ of the lead nitrate solution (1300 ppm) prepared above. The three tubes and their contents were vortexed, tightly secured on the rack of a heavy duty Eberbach 6000 shaker, and agitated for 24 hours at room temperature

\section{Sample Preparation and Analysis}

\subsection{Sample Preparation}

After $24 \mathrm{hrs,}$ the shaker was stopped and the tubes and their contents were centrifuged at $3000 \mathrm{rpm}$ for ten minutes. The resulting clear supernatant in each tube was transferred into another labeled clean centrifuge tube. All the labeled centrifuge tubes with their liquid contents were sent to PACE Analytical Services, Inc for lead analysis using EPA Method 6010. Note that PACE Analytical Services, Inc. is a commercial environmental laboratory that is accredited in accordance to the National Environmental Laboratory Accreditation Conference (NELAC).

\subsection{Sample Analysis for Lead after Reaction}

After the reaction period, the lead concentration (in ppm) in the liquid from each reaction tube was analyzed using EPA Method 6010 (Inductively Coupled Plasma-Atomic Emission Spectrometry (ICP-AES)).

\section{Results}

Data on Table 1 show the amount of lead in ppm remaining in each reaction tube after contaminated water was treated with leafy vegetable supernatants for $24 \mathrm{hrs}$ and the percent of lead removed relative to the control: Control (1277, 0\%); Spinach (17.7, 98.6\%); Mustard Green (25.2, 98\%); Collard Green (2.4, 99.8\%); and Bitter Leaf $(534,58 \%)$ while Figures 1(a) and 1(b) show the amount of lead remaining in the reaction mixture after vegetative treatment and the percent of lead removed, respectively.

\section{Discussions}

On Leafy Vegetable Supernatants: The results on Table 1 and Figures 1(a) and 1(b) showed that the supernatants from all leafy vegetables (Collard Green, Spinach and Mustard Green) removed over $95 \%$ of the lead from contaminated water except bitter leaf. Furthermore, Collard Green, Spinach, and Mustard Green exhibited equal potential for lead removal.

On Fruity \& Root Vegetable Supernatants: The data on Table 2 and Figures 2(a) and 2(b) below showed that Carrot, Green Bell Pepper and Yellow Bell Pepper removed over $95 \%$ of the lead from the contaminated water while Red Bell Pepper and Tomatoes only removed 90\% and $83 \%$ of the lead, respectively. Thus, all vegetables were able to remove $90 \%$ of the lead except Bitter Leaf $(58 \%)$ and Tomatoes $(82.7 \%)$.

On Fruit Supernatants: The data on Table 3 and Figures 3(a) and 3(b) below suggest that grape (white and red) removed $\geq 90 \%$ of the lead from contaminated water while lime removed only $57.6 \%$ of the lead. Further examination of the data for all plants on Figures 4(a) and 4(b) suggest a decreased potential for lead removal by supernatants from acidic vegetables and fruits (Bitter 
Table 1. Residual \& removed lead in contaminated water after treatment with leafy vegetables.

\begin{tabular}{ccccc}
\hline Sample & {$[\mathrm{Pb}]$ in ppm } & Std. Dev. & Std. Err. & \% Lead Removed \\
\hline Control (Ctr) & 1277 & 37.86 & 21.86 & 0 \\
Spinach (Sp) & 17.7 & 0.56 & 0.32 & 98.6 \\
Mustard Green (MG) & 25.2 & 0.61 & 0.35 & 98 \\
Collard Green (CG) & 2.4 & 0.015 & 0.0088 & 99.8 \\
Bitter Leaf (BL) & 534 & 51.6 & 29.81 & 58 \\
{$[50 \%$ Pb Ctrluted Pb] } & 710 & 5.03 & 2.91 & 0 \\
\hline
\end{tabular}

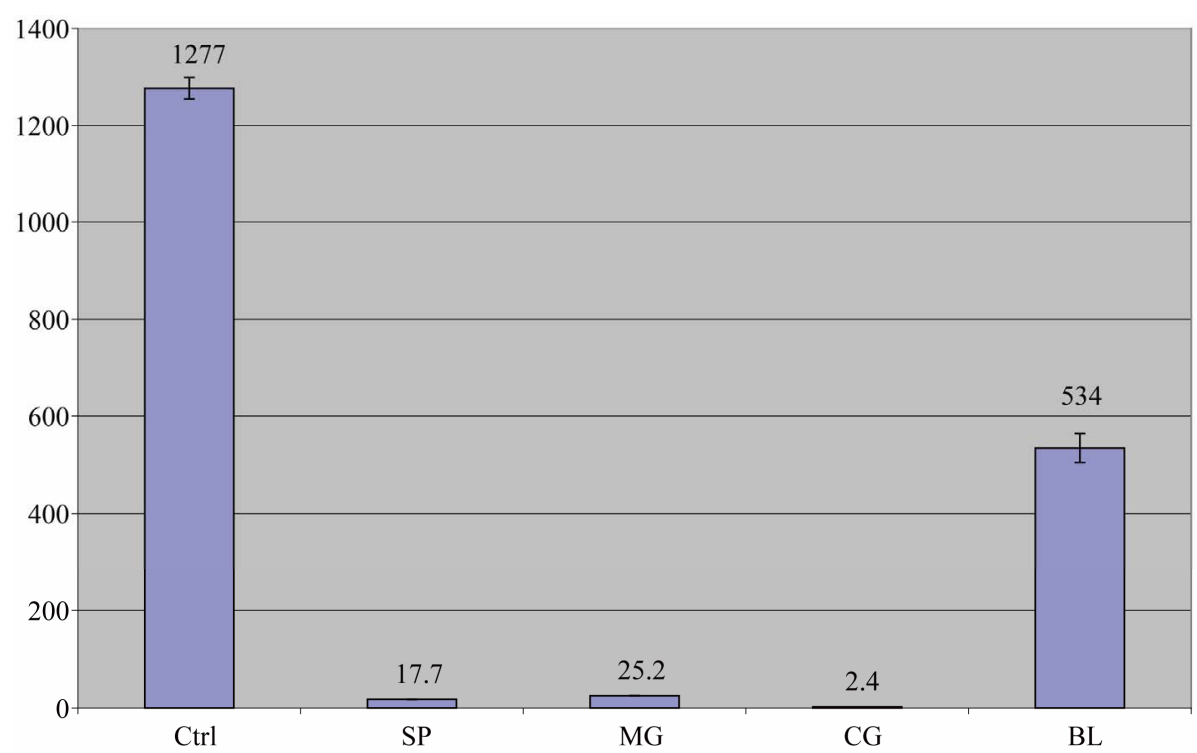

(a)

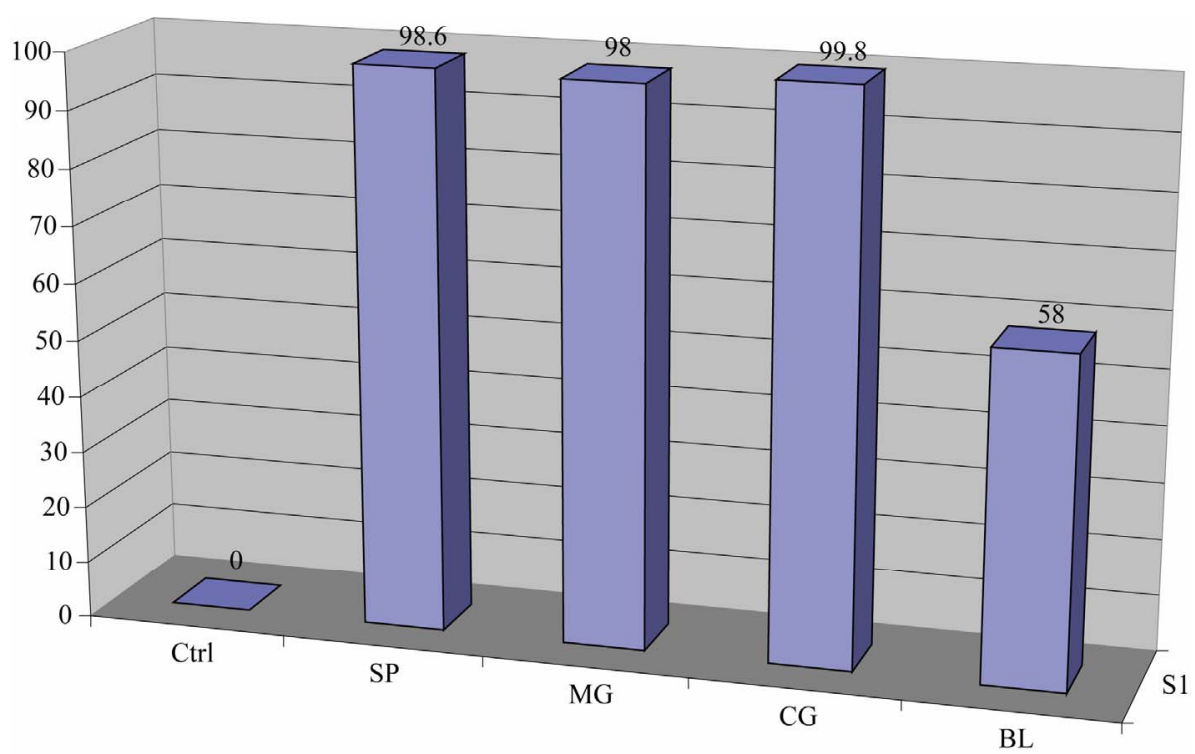

(b)

Figure 1. (a) Lead concentration remaining after contaminated water was treated with leafy vegetables; (b) Percent lead removed after contaminated water was treated with leafy vegetable supernatants for $24 \mathrm{hr}$. 
Table 2. Residual \& removed lead in contaminated water after treatment with fruity \& root vegetables.

\begin{tabular}{ccccc}
\hline Sample & {$[\mathrm{Pb}]$ in ppm } & Std. Dev. & Std. Err. & \% Lead Removed \\
\hline Control (Ctr) & 1277 & 37.86 & 21.86 & 0 \\
Green Bell Pepper (GBP) & 30.7 & 3.3 & 1.9 & 97.6 \\
Yellow Bell Pepper (YBP) & 31.4 & 1.1 & 0.65 & 97.5 \\
Red Bell Pepper (RBP) & 79.9 & 1.3 & 0.75 & 93.7 \\
Tomatoes (Tom) & 220.6 & 55 & 31.8 & 82.7 \\
Carrot (Car) & 20.6 & 0.61 & 0.35 & 98 \\
{$[50 \%$ Pb Ctrluted $\mathrm{Pb}]$} & 710 & 5.03 & 2.91 & 0 \\
\hline
\end{tabular}

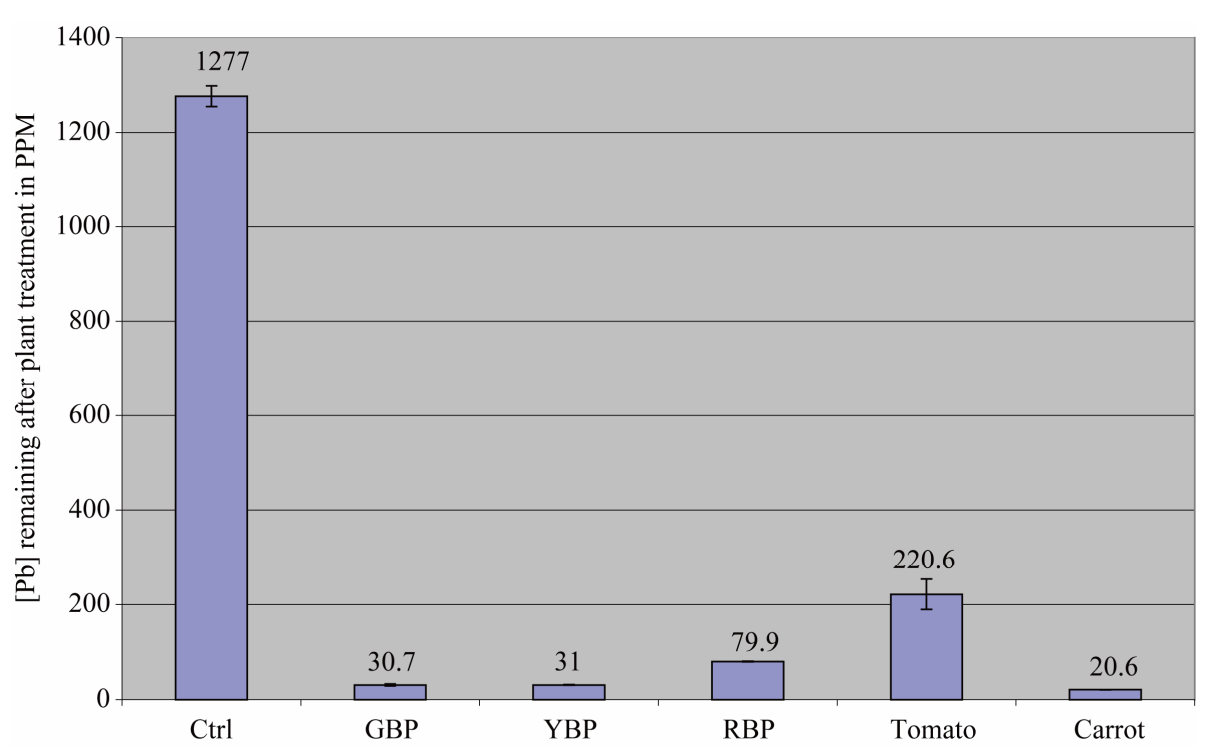

(a)

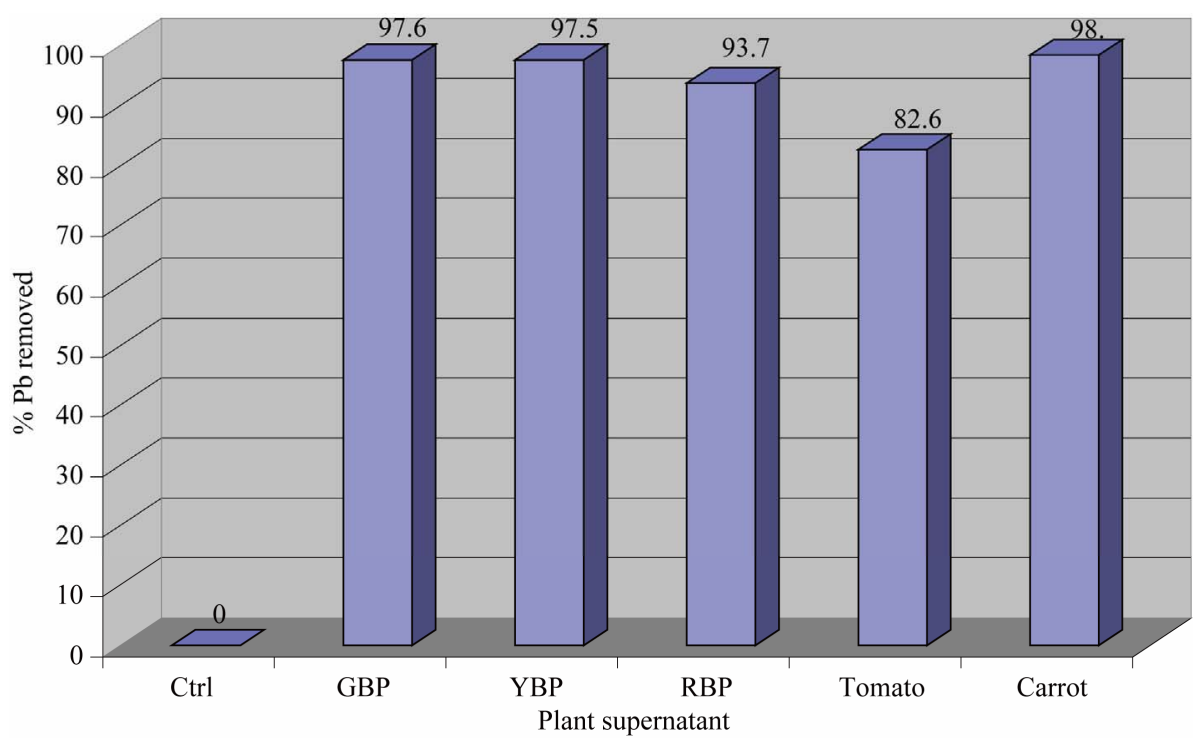

(b)

Figure 2. (a) Lead concentration remaining after contaminated water was treated with fruity vegetable; (b) Percent lead removed after contaminated water was treated with fruity vegetables. 
Table 3. Residual \& removed lead in contaminated water after treatment with fruits.

\begin{tabular}{ccccc}
\hline Sample & {$[\mathrm{Pb}]$ in ppm } & Std. Dev. & Std. Err. & \% Lead Removed \\
\hline Control (Ctr) & 1277 & 37.86 & 21.86 & 0 \\
White Grape (WG) & 46.0 & 13.4 & 7.75 & 96 \\
Red Grape (RG) & 89.9 & 5.5 & 3.18 & 92.9 \\
Lime (LM) & 540.8 & 70.7 & 40.82 & 57.6 \\
$50 \%$ Diluted Pb Ctrl & 710 & 5.03 & 2.91 & 0 \\
\hline
\end{tabular}

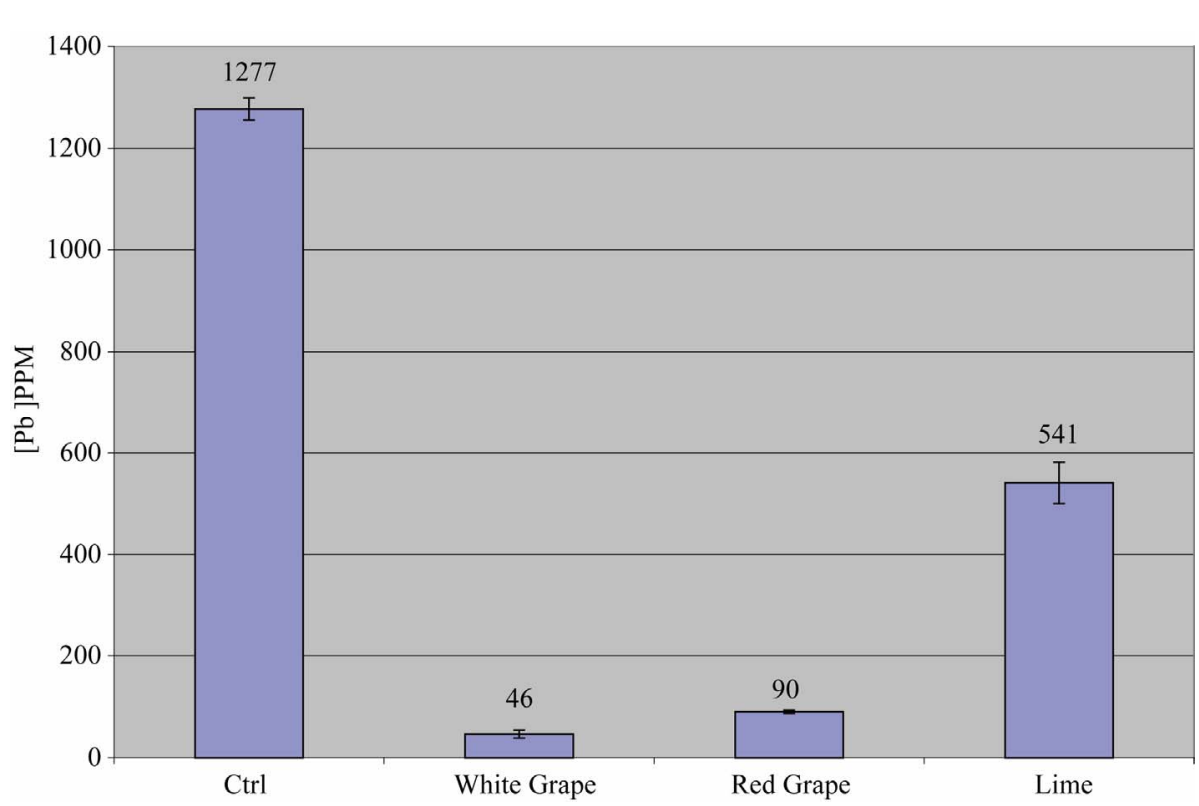

(a)

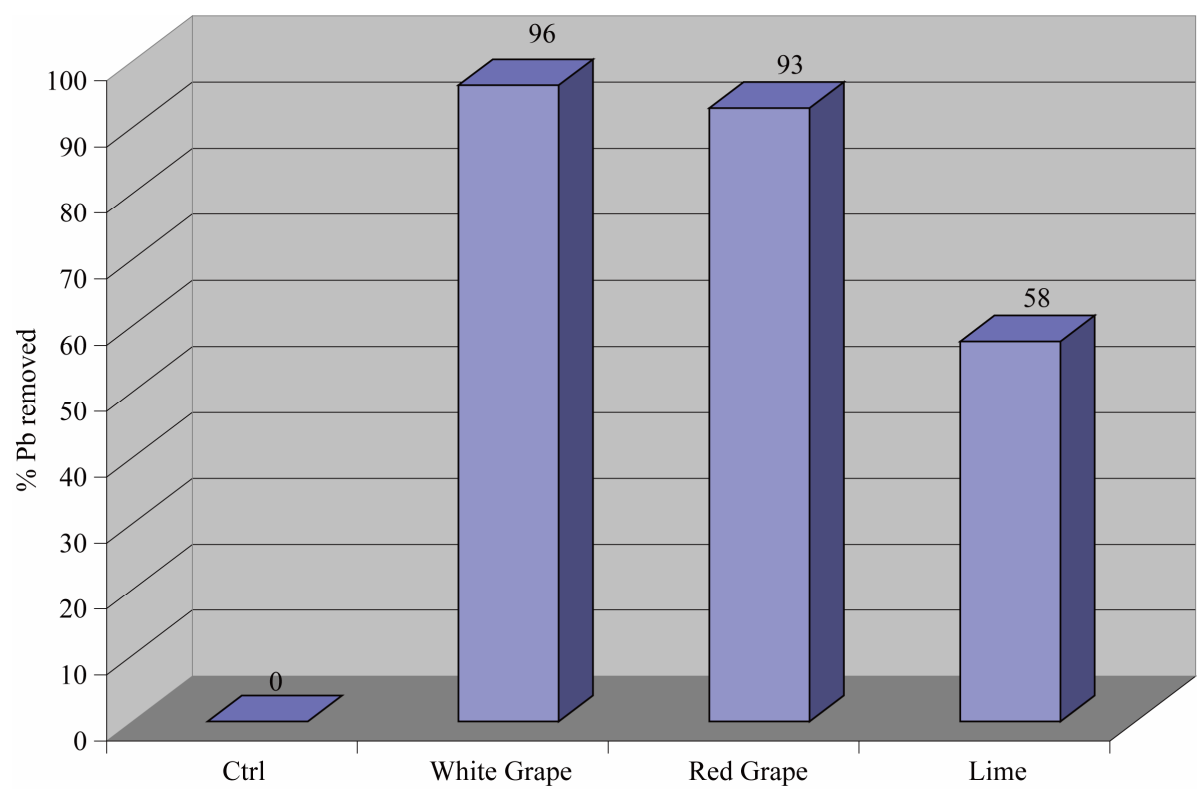

(b)

Figure 3. (a) Lead concentration remaining after contaminated water was treated with fruit; (b) Percent lead removed after contaminated water was treated with fruits. 


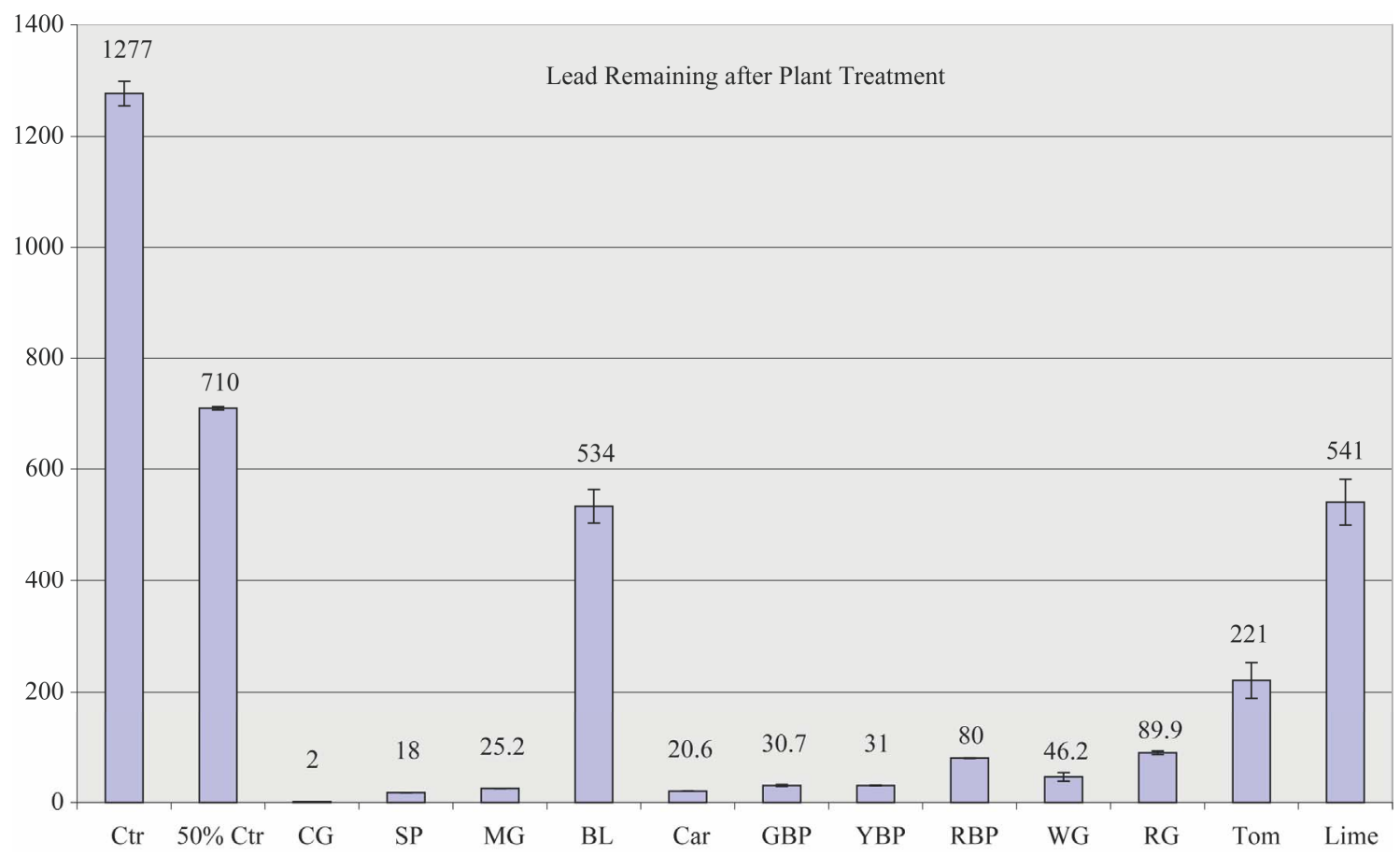

(a)

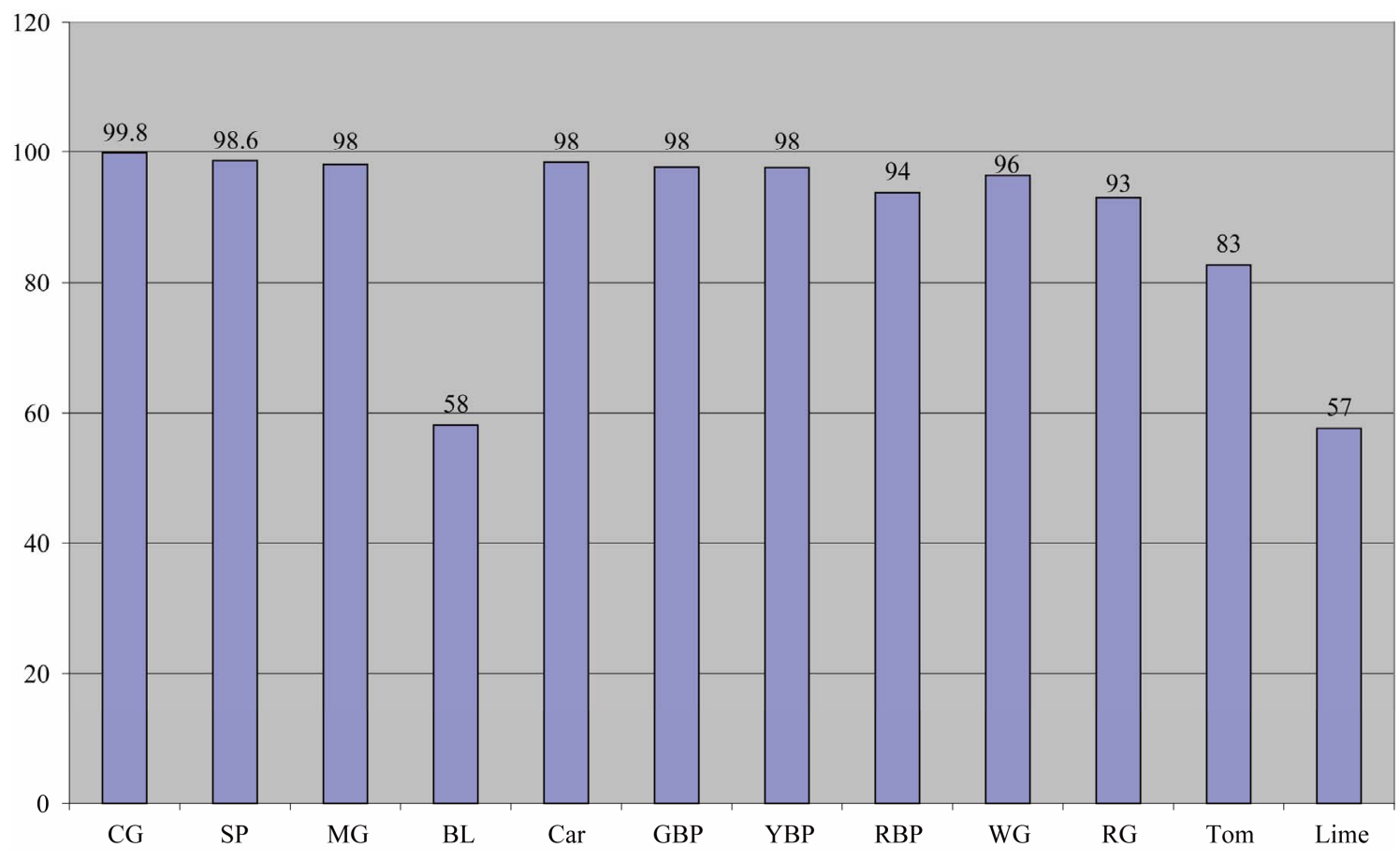

(b)

Figure 4. (a) Lead removal by all plant supernatants; (b) Percentage lead removed by all plants.

Leaf (58\%), Lime (58\%), and Tomatoes (83\%)) when compared to other plants.

Thus, the order of lead removal is Collard Green (99.8\%) $>$ Spinach $(98.8 \%)>$ Mustard Green (98\%) Carrot (98\%) Green Bell Pepper (97.6\%) Yellow Bell Pepper $(97.5 \%)>$ White Grape $(96 \%)>$ Red Bell Pepper
$(93.7 \%)>$ Red Grape $(92.9 \%)>$ Tomatoes $(82.7 \%)>$ Bitter Leaf $(58 \%)>$ Lime $(57.6 \%)$.

The percent of lead removed by the supernatants is based on the initial lead concentration assumed to be $1277 \mathrm{ppm}$. Although we set out to prepare $1300 \mathrm{ppm}$ of lead stock solution; however, the average ICP result of 
the control after $24 \mathrm{hrs}$ was $1276.66 \mathrm{ppm}$.

\section{Conclusion}

Lead contamination represents one of the most important problems of contamination at present due to its high toxicity and cumulative properties. Furthermore, environmental lead exposure is a public health problem of global dimension. The results clearly demonstrate that the supernatants from vegetables and fruits are very effective in removing lead from contaminated water. The order of percent lead removal is Collard Green (99.8\%) > Spinach (98.7\%) > Mustard Green (98.2\%) > Green Bell Pepper $(97.8 \%)>$ Yellow Bell Pepper $(97.75 \%)>$ White Grape (96.7\%) > Carrot (95.5\%) > Red Bell Pepper (94.28\%) > Red Grape $>93.5 \%>$ Tomatoes $(84 \%)>$ Bitter Leaf $(61 \%)>$ Lime $(57 \%)$. The study concludes that liquid supernatants from pureed edible leafy, fruity, and root vegetables as well as fruits used in this study can effectively remove lead from contaminated water. Thus, this project represents a development of a highly effective vegetative treatment of lead contaminated water.

\section{Acknowledgements}

We thank Dr. Abdalla Darwish and the Dillard University LAMP Program for sample analysis, Victor Ogburie and Stephen Igwe.

\section{REFERENCES}

[1] P. Gottesfeld and C. R. Cherry, "Lead Emissions from Solar Photovoltaic Energy Systems in China and India," Energy Policy, Vol. 39, No. 9, 2011, pp. 4939-4946. doi:10.1016/j.enpol.2011.06.021

[2] P. A. Meyer, M. J. Brown and H. Falk, "Global Approach to Reducing Lead Expo Sure and Poisoning," Mutation Research, Vol. 659, No. 1-2, 2008, pp. 166-175. doi:10.1016/j.mrrev.2008.03.003

[3] L. J. Fewtrell, A. Pruss-Ustun, P. Landrigan and J. L. Ayuso-Mateos, "Estimating the Global Burden of Disease of Mild Mental Retardation and Cardiovascular Diseases from Environmental Lead Exposure," Environmental Research, Vol. 94, No. 2, 2004, pp. 120-133. doi:10.1016/S0013-9351(03)00132-4

[4] U. Forstner, "Land Contamination by Metals: Global Scope and Magnitude of Problem," In: H. E. Allen, C. P. Huang, G. W. Bailey and A. R. Bowers, Eds., Metal Speciation and Contamination of Soil, CRC Press, Boca Raton, 1995, p. 133.

[5] D. A. Peel, "Environment Research: Is Lead Pollution of the Atmosphere a Global Problem?" Nature, Vol. 323, No. 6085,1986 , p. 200. doi: $10.1038 / 323200 \mathrm{a} 0$

[6] M. Weitzman, A. Aschengrau, D. Bellinger and R. Jones, "Lead Contaminated Soil Abatement and Urban Children's Blood Lead Levels," The Journal of the American Medical Association, Vol. 269, No. 13, 1993, pp. 1647-
1654. doi:10.1001/jama.1993.03500130061033

[7] H. W. Mielke, J. L. Adams, P. L. Reagan and P. W. Mielke Jr., "Soil-Dust Lead and Childhood Lead Exposure as a Function of City Size and Community Traffic Flow: The Case for Lead Contaminated Soil Abatement in Minnesota," In: B. E. Davies and B. G. Wixson, Eds., Lead in Soil: Issues and Guidelines, (Suppl 9), Environmental Geochemistry and Health, 1989, pp. 253-271.

[8] T. Sardis, M. K. Chettri, A. Papaioannou, G. Zachariadis and J. Stratis, "A Study of Metal Distribution from Fuels, Using Trees as Biological Monitors," Ecotoxicogy and Environmental Safety, Vol. 48, No. 1, 2001, pp. 27-35. doi:10.1006/eesa.2000.2001

[9] D. W. Blowes, E. J. Readon, J. L. Jambor and J. A. Cherry, "The Formation and Potential Importance of Cemented Layers in Inactive Sulfide Mine Tailings," Geochimica Cosmoshimica Acta, Vol. 55, No. 4, 1991, pp. 965-978. doi:10.1016/0016-7037(91)90155-X

[10] J. Cotter-Howells and I. Thornton, "Sources and Pathways of Environmental Lead to Children in a Derbyshire Mining Village," Environmental Geochemistry and Health, Vol. 13, No. 2, 1991, pp. 127-135.

[11] T. J. Logan and R. L. Chaney, "Utilization of Municipal Wastewater and Sludge on Land: Metals," In: A. L. Page, T. L. Gleason III., J. E. Smith Jr., I. K. Islander and L. E. Sommers, Eds., Proceeding Sponsored by US Environmental Protection Agency, US Army Corps of Engineers, USDA of 1983 Workshop on Utilization of Municipal Wastewater and Sludge on Land, 1983.

[12] Q. Y. Ma, T. J. Logan and S. J. Traina, "Lead Immobilization from Aqueous Solutions and Contaminated Soils Using Phosphate Rocks," Environmental Science and Technology, Vol. 29, 1995, pp. 1118-1126.

[13] V. Gounaris, P. R. Anderson and T. M. Holsen, "Characteristics and Environmental Significance of Colloids in Landfill Leachate," Environmental Science and Technology, Vol. 27, No. 7, 1993, pp. 1381-1387. doi: $10.1021 / \mathrm{es} 00044 \mathrm{a} 013$

[14] R. Chaney and H. Mielke, "Standard for Soil Lead Limitations in the United States, Trace Substance," Environmental Health, Vol. 20, 1986, p. 358.

[15] A. L. Clune1, H. Falk1, M. P. H. Anne and M. Riederer1, "Mapping Global Environmental Lead Poisoning in Children," Journal of Health Pollution, Vol. 1, No. 2, 2011, pp. 16-25.

[16] H. Falk, "International Environmental Health for the Pediatrician: Case Study of Lead Poisoning," Pediatrics, Vol. 112, No. 1, 2003, pp. 259-264.

[17] P. A. Meyer, M. J. Brown and H. Falk, "Global Approach to Reducing Lead Exposure and Poisoning," Mutation Research, Vol. 659, No. 1-2, 2008, pp. 166-175. doi:10.1016/j.mrrev.2008.03.003

[18] L. J. Fewtrell, A. Pruss-Ustun, P. Landrigan and J. L. Ayuso-Mateos, "Estimating the Global Burden of Disease of Mild Mental Retardation and Cardiovascular Diseases from Environmental Lead Exposure," Environmental Research, Vol. 94, No. 2, 2004, pp. 120-133. doi:10.1016/S0013-9351(03)00132-4 
[19] M. A. Smith, "Lead in History," In: R. Lansdown and W. Yule, Eds., The Lead debate: The Environmental Toxicology and Child Health, Taylor \& Francis, London, 1984, pp. 7-24.

[20] G. W. Goldstein, "Neurological Concepts of Lead Poisoning in Children," Pediatric Annals, Vol. 21, No. 6, 1992, pp. 384-388.

[21] S. Tong, "Lead Exposure and Cognitive Development: Persistence and a Dynamic Pattern," Journal of Pediatrics and Child Health, Vol. 34, No. 2, 1998, pp. 114-118.

[22] M. L. Miranda, K. Dohyeong, M. A. Galeano, C. J. Paul, A. P. Hull and S. P. Morgan, "The Relationship between Early Child Hood Blood Lead Levels and Performance on End-of-Grade Tests," Environmental Health Perspectives, Vol. 115, No. 8, 2007, pp. 1242-1247.

[23] R. L. Canfield, C. R. Henderson Jr., D. A. Cory-Slechta, C. Cox, T. A. Jusko and B. P. Lanphear, "Intellectual Impairment in Children with Blood Lead Concentrations below $10 \mu \mathrm{g}$ Per Deciliter," The New England Journal of Medicine, Vol. 348, 2003, pp. 1517-1526. doi:10.1056/NEJMoa022848

[24] H. Needleman, C. McFarland, R. Ness, S. Fienberg and M. Tobin, "Bone Lead Levels in Adjudicated Delinquents: A Case Control Study," Neurotoxicology and Teratology, Vol. 24, No. 6, 2003, pp. 711-717.

[25] R. A. Shih, H. Hu, M. G. Weisskopf and B. S. Schwartz, "Cumulative Lead Dose and Cognitive Function in Adults: A Review of Studies That Measured Both Blood Lead and Bone Lead," Environmental Health Perspectives, Vol. 115, No. 3, 2007, pp. 483-492.

[26] J. L. Lin, D. T. Lin-Tan, K. H. Hsu and C. C. Yu, "Environmental Lead Exposure and Progression of Chronic renal Diseases in Patients without Diabetes," The New England Journal of Medicine, Vol. 348, 2003, pp. 277-286.

[27] V. Medina, S. L. Larson, L. Agwaramgbo, W. Perez and L. Escalon, "Treatment of Trinitrotoluene by Crude Plant Extracts," Chemosphere, Vol. 55, No. 5, 2004, pp. 725732. doi:10.1016/jchemshephere.200312.014

[28] L. Agwaramgbo, "Evaluation of the Fate of RDX in Soils and Plants: Uptake, Transport, Accumulation, Degradation, and Release by Plants" US Army Research Office, Contract \# DAAD19-02-D-0001, Battelle, Scientific Services TCN 03-123, 2003.

[29] V. F. Medina, S. Larson, L. Agwaramgbo, W. Perez and L. Escaon, "Treatment of Trinitrotoluene by Crude Plant Extracts," Chemosphere, Vol. 55, No. 5, 2004, pp. 725732. doi:10.1016/j.chemosphere.2003.12.014
[30] N. Merkl, R. Schutze-Kraft and C. Infante, "Assessment of Tropical Grasses and Legumes for the Phytoremediation of Petroleum Contaminated Soils," Water, Air, and Soil Pollution, Vol. 165, No. 1-4, 2005, pp. 195-209. doi:10.1007/s11270-005-4979-y

[31] A. S. Moffat, "Plants Proving Their Worth in Toxic Metal Cleanup," Science, Vol. 269, 1995, pp. 302-303. doi: $10.1126 /$ science.269.5222.302

[32] M. M. Lasat, "Phytoextraction of Toxic Metals: A Review of Biological Mechanisms," Journal of Environmental Quality, Vol. 31, 2002, pp. 109-120.

[33] R. D. Armstrong, M. Todd, J. W. Atkinson and K. Scott, "Selective Electrodeposition of Metals from Simulated Waste Solutions," Journal of Applied Electrochemistry, Vol. 26, No. 4, 1996, pp. 379-384. doi:10.1007/BF00251322

[34] T. R. Harper and N. W. Kingham, "Removal of Arsenic from Wastewater Using Chemical Precipitation Methods," Water Environment Research, Vol. 64, No. 3, 1992, pp. 200-203. doi:10.2175/WER.64.3.2

[35] A. El Nemr, A. El Sikaily, A. Khaled and O. Abdelwahab, "Removal of Toxic Chromium(VI) from Aqueous Solution by Activated Carbon Using Casuarina equisetifolia," Chemistry and Ecology, Vol. 23, No. 2, 2007, pp. 119129. doi: $10.1080 / 02757540701197754$

[36] A. El Nemr, "Pomegranate Husk as an Adsorbent in the Removal of Toxic Chromium from Wastewater," Chemistry and Ecology, Vol. 23, No. 5, 2007, pp. 409-425. doi:10.1080/02757540701653350

[37] S. S. Baral, S. N. Das, P. Rath, G. R. Chudhury and Y. V. Swamy, "Removal of Cr(VI) from Aqueous Solution Using Waste Weed, Salvinia cucullata," Chemistry and Ecology, Vol. 23, No. 2, 2007, pp. 105-117. doi:10.1080/02757540701197697

[38] T. K. Radicic and S. Raicevic, "In Situ Lead Stabilization Using Natural and Synthetic Apatite," Chemical Industry \& Chemical Engineering Quarterly, Vol. 14, No. 4, 2008, pp. 269-271. doi:10.2298/CICEQ0804269K

[39] L. Agwaramgbo, E. Agwaramgbo, C. Mercadel, S. Edwards and E. Buckles, "Lead Remediation of Contaminated Water by Charcoal, LA Red Clay, Spinach, and Mustard Green," Journal of Environmental Protection, Vol. 2, No. 9, 2011, pp. 1240-1244. doi:10.4236/jep.2011.29142

[40] Lovell Agwaramgbo and Travis Demley, Unpublished result, "Lead Removal from Contaminated Water by Salmon Fish Bone,” Unpublished Work, 2011. 